\title{
IDENTIDADES ESTRANGEIRAS NA NARRRATIVA DE UMA TELENOVELA BRASILEIRA: O PROCESSO DE RECEPÇÃO DE CAMINHO DAS ÍNDIAS
}

\author{
Foreign identities in the narrative of a brazilian telenovela: the process of \\ reception of india: a love story
}

\section{Identidades extranjeras en la narrativa de una telenovela brasileña: el proceso de recepción de india, una historia de amor}

Paola Luciana Rodriguez Peciar Doutora em Antropologia Social pela Universidade Federal de Santa Catarina - UFSC paola.peciar@gmail.com

Maria Catarina Chitolina Zanini Doutora em Antropologia Social pela Universidade de São Paulo - USP, Professora Titular da Universidade Federal de Santa Maria - UFSM zanini.ufsm@gmail.com

\section{Resumo}

Assistir a telenovelas é um hábito bastante arraigado no modo de vida dos brasileiros que também é adotado por imigrantes que residem no Brasil. As considerações deste artigo se baseiam no processo de recepção de imigrantes indianos da telenovela Caminho das Índias, cuja narrativa versava sobre a identidade étnica indiana em contraponto aos costumes do nosso país. O objetivo geral foi o de compreender a experiência desses imigrantes ao assistirem a uma telenovela que veiculava informações sobre seu país de origem e seu povo. Dentre as considerações alcançadas, entendemos que as narrativas das telenovelas são vivenciadas reflexivamente e que esse processo se configura como um rico objeto de pesquisa para a área da Antropologia, quando dialoga com os conhecimentos produzidos pela área da Comunicação.

Palavras-chave: Processo de recepção. Identidade Étnica. Telenovela.

\begin{abstract}
Watching soap operas is a habit that is deeply ingrained in the Brazilian way of life, which is also adopted by immigrants that reside in Brazil. The considerations in this paper are based on the reception process of Indian immigrants of the soap opera 'India: A Love Story' whose narrative dealt with the Indian ethnic identity in contrast to the customs of our country. The general objective was to understand the experience these immigrants have while watching a soap opera that broadcasted information about their country of origin and their people. Among the findings, it was discovered that the narratives from soap operas are experienced reflexively. Also considered is that this process is configured as a rich research object for the
\end{abstract}


area of anthropology, when it dialogues with the knowledge produced by the area of communication.

Key words: Reception Process. Ethnic Identity. Soap opera.

\section{Resumen}

Asistir a las telenovelas es un hábito bastante arraigado en el modo de vida de los brasileños que también es adoptado por inmigrantes que residen en Brasil. Las consideraciones de este artículo se basan en el proceso de recepción de inmigrantes hindúes de la telenovela India, una historia de amor, cuya narrativa versaba sobre la identidad étnica hindú en contrapunto a las costumbres de nuestro país. El objetivo general fue el de comprender la experiencia de esos inmigrantes de seguir a una telenovela que vinculaba informaciones sobre su país de origen y su pueblo. Entre las consideraciones alcanzadas, entendemos que las narrativas de las telenovelas son vivenciadas reflexivamente y que ese proceso se configura como un rico objeto de investigación para el área de la Antropología, cuando dialoga con los conocimientos producidos por el área de la Comunicación.

Palabras clave: Proceso de Recepción. Identidad Étnica. Telenovela.

\section{INTRODUÇÃO}

Exibida pela primeira vez pela Rede Globo de Televisão, entre os meses de janeiro e setembro de 2009, a telenovela Caminho das Índias apresentou um conjunto de contrapontos entre as peculiaridades da cultura e da identidade étnica indiana ${ }^{1}$ e os costumes brasileiros. $\mathrm{Ou}$ seja, se propunha a apresentar disparidades entre os modos de vida de brasileiros e de indianos através da encenação da convivência entre eles ${ }^{2}$.

A história contada por Caminho das Índias foi ambientada nos dois países: havia brasileiros que se dirigiam à Índia, e indianos que vinham ao Brasil, proporcionando o cruzamento de imagens, paisagens e cenários variados. Essa perspectiva imagética transnacional (BLANC et al, 1995), mesclando línguas e universos familiares e paisagísticos, procurava trazer o olhar de universos culturais em diálogo e trânsito, via a apresentação de relações sociais diversas como de parentesco, negócios, amizades, romances, entre outras. E,

\footnotetext{
${ }^{1}$ Por identidade étnica, referimo-nos ao trato da identidade de "indiano", no encontro com a sociedade brasileira, e não necessariamente às diversidades presentes no estado-nacional indiano. Na mesma esteira de pensamento, por grupo étnico, entende-se, nesta pesquisa, aqueles que se percebem e são percebidos como distintos por meio de invocação de fronteiras adscritivas (vide BARTH, 1998). No caso por nós aqui apresentado, os entrevistados apontam a origem comum (indiana) e suas trajetórias de imigrantes, como um sinal de diferenciação.

${ }^{2}$ Caminho das Índias foi reexibida pela mesma emissora entre os meses de julho de 2015 e abril de 2016.
} 
sobretudo, enfatizava as diferenças do modo de vida daqueles estrangeiros por meio da narrativa sobre as particularidades do sistema de castas ${ }^{3}$.

No início de nossa pesquisa, nosso questionamento girava em torno de sobre quais bases era construída a narrativa de Caminho das Índias acerca do sistema de castas indiano e sobre a identidade daquele povo. Como, também, se a telenovela dialogava com a literatura antropológica produzida sobre a Índia, especialmente com a obra de Dumont (2008). Por meio da realização de um contraponto entre as informações contidas na etnografia de Louis Dumont sobre a Índia e a narrativa da telenovela sobre aquele povo, notamos que muitas das informações veiculadas por ela coincidiam com a referida obra, mas que outras não tinham tanta relação assim.

A questão histórica e temporal da produção dos estudos e da exibição da telenovela foi levada em consideração. Contudo, a possibilidade narrativa desse sistema (de castas) era algo extremamente rico e provocador de reflexões, tanto para nós pesquisadoras como para os imigrantes indianos entrevistados. Isso porque a forma como a narrativa de uma telenovela é emitida e (re)produzida, provoca, muitas vezes, reações, tornando-se passível de ser aceita ou não, questionada e/ou reelaborada. Trata-se de uma possibilidade dialógica em níveis amplos (OLIVEIRA e RONSINI, 2007; ZANINI, 2007; PECIAR, 2010). E, nesses termos, uma telenovela pode sofrer mediações culturais diversas, que se manifestam em reapropriações de sentido via questionamentos, refrações e, mesmo por uma ampla aceitação.

Assim, por meio de pesquisa etnográfica e em diálogo com os estudos de recepção da área da Comunicação, nosso objetivo foi o de observar e compreender como a telenovela Caminho das Índias foi recebida por imigrantes indianos residentes na cidade de Santa Maria, no estado do Rio Grande do Sul (RS). Nossos entrevistados pertencem a duas famílias distintas, uma oriunda de Goa e outra de Chenai, que imigraram para o Brasil na década de $1970^{4}$.

O extrato do trabalho de campo que iremos apresentar, trata do processo de recepção da narrativa de Caminho das Índias sobre o sistema de castas indiano ${ }^{5}$.

\footnotetext{
${ }^{3} \mathrm{O}$ sistema de castas é uma divisão social com base no princípio da hierarquia presente na Índia e, também, em alguns outros países cuja religião é o hinduísmo.

${ }^{4} \mathrm{Na}$ cidade de Santa Maria não há uma colônia indiana de imigração. O processo imigratório de nossos entrevistados é praticamente de trajetória individual e não há indícios de outras famílias indianas residentes na cidade. Eles possuem filhos e netos nascidos no Brasil, e mantêm contato com parte de suas famílias que reside na Índia via telefone, internet e através de visitas esporádicas ao país de origem.

${ }^{5}$ Contudo, o universo da pesquisa foi muito mais amplo, pois as entrevistas discorreram também sobre outras questões da narrativa da telenovela em relação à cultura e à identidade étnica dos indianos, como, por exemplo, sobre o tema do casamento inter-étnico.
} 
Embasamo-nos, para esta pesquisa, na noção de mediação de Martín-Barbero (2003). E, no que tange especificamente aos processos de recepção das telenovelas e ao tema da identidade étnica, ancoramo-nos nos estudos de Leal (1990), Kottak (1990), Borelli (2001), Lopes et al (2002), Almeida (2003), Oliveira e Ronsini (2007), Hamburger (2005), Zanini (2007), Magalhães (2008), entre outros, que apontam para a riqueza simbólica, narrativa e social dos processos mencionados.

Esclarecemos que o texto que se segue trará, na Seção 2, apontamentos gerais sobre os estudos de recepção após os anos 1980, acerca das telenovelas e o olhar antropológico sobre as mesmas. Na Seção 3, haverá um extrato de nosso trabalho de campo em torno do processo de recepção de nossos interlocutores, com base na transcrição e apresentação de uma das cenas de Caminho das Índias com respeito à narrativa sobre o sistema de castas. Finalmente, na Seção 4, alguns apontamentos sobre as particularidades da relação dos espectadores com as telenovelas no Brasil.

\section{ESTUDOS DE RECEPÇÃO E TELENOVELAS: MUDANÇAS PARADIGMÁTICAS PÓS ANOS 1980 COM MARTÍN-BARBERO E O OLHAR ANTROPOLÓGICO}

A partir dos anos 1980 os estudos de recepção adquiriram uma abordagem inovadora em virtude da noção de mediação de Martín-Barbero (2003) ${ }^{6}$. O autor chamava a atenção para o fato de que a experiência da recepção dos discursos/narrativas midiáticos de massa, por parte dos receptores, não se dava, invariavelmente, de modo homogêneo e passivo. Ao contrário, havia outras possibilidades e formas de recepção do discurso midiático em que as pessoas ofereciam resistência à tentativa de difusão de valores e disseminação de consensos por parte dos meios de comunicação. Martín-Barbero (2003) desenvolveu uma perspectiva alternativa sobre os fenômenos comunicacionais e os poderes de manipulação ou influência dos meios. Em outras palavras, ele sinalizou a ocorrência de múltiplas possibilidades de interpretação, apropriação e ressignificação que uma dada mensagem podia sofrer por parte das pessoas.

No que tange às telenovelas, os estudos de recepção abriram a possibilidade de identificar que um mesmo texto permite leituras plurais. Nessa esteira de pensamento, a obra "A leitura social da telenovela das oito" da antropóloga Ondina Leal (1990) apresenta como

\footnotetext{
6 A primeira publicação da obra de Martín-Barbero no Brasil, intitulada "Dos Meios às Mediações: comunicação, cultura e hegemonia", ocorreu no ano de 1997. Contudo, sua publicação original, em língua espanhola, foi editada dez anos antes.
} 
uma dada mensagem dos meios de comunicação de massa é assistida, entendida e reelaborada por grupos de diferentes classes sociais. O meio de comunicação tomado como referência pela autora foi a telenovela Sol de Verão, da Rede Globo, exibida entre 1982 e 1983, por meio de uma etnografia da audiência ${ }^{7}$. Cabe ressaltar que estudos de recepção sobre telenovelas, posteriores à pesquisa pioneira dessa autora, também são identificados sob o título de etnografia da recepção, conforme esclarece a antropóloga Esther Hamburguer:

A chamada "etnografia da recepção" da televisão seria uma alternativa capaz de fornecer uma descrição compreensiva sobre o que os telespectadores vêem em determinados programas. A observação participante em contextos de recepção seria capaz de ir além do que espectadores falam ou escrevem quando perguntados, permitindo a abordagem de como a TV, ou determinados programas, se insere no cotidiano das pessoas que assistem. Ou seja, vislumbrando conexões entre o ato de assistir à televisão e as rotinas cotidianas dos telespectadores (HAMBURGUER, 2005, p.17).

A pesquisa de Leal (1990) foi , nos anos 1980, um dos trabalhos pioneiros no Brasil inaugurando e estabelecendo um novo modo de fazer etnográfico, em que o pesquisador acompanhava a recepção do meio de comunicação junto ao grupo estudado. O pesquisador se mantinha presente no momento em que as pessoas assistiam à telenovela ou outros programas, no intuito de analisar a experiência de assistir televisão no cotidiano das pessoas. Conforme essa autora:

A novela das oito é uma forma genérica que os produtores, os receptores e as crônicas dos jornais referem-se às telenovelas que são emitidas de segunda a sábado, continuamente, indicando, na forma de se referirem ao programa, a familiaridade cotidiana e a predominância de um meio de comunicação, de uma emissora, de um horário e de um determinado tipo de programação. A novela das oito é o programa que por maior período de tempo na história da televisão no Brasil mantém o mais alto índice de audiência e a maior dispersão de audiência entre as diferentes classes sociais. É um programa característico da indústria cultural, no sentido de ser racionalmente produzido visando um público massivo. É também um tipo de produção onde há uma grande inversão de capital e um efetivo aprimoramento técnico do produto, tendo esta produção e produções correlatas (os curta-metragem e as séries que empregam a mesma tecnologia das novelas) um mercado significativo fora do Brasil (LEAL, 1990, p.12).

\footnotetext{
7 A etnografia da audiência é um modo específico de abordagem da comunicação de massa utilizado pela Antropologia, que pode ser situada dentro de um campo mais amplo denominado Estudos de Recepção (MAGALHÃES, 2008).
} 
Também, a questão do poderio da televisão ou das empresas, juntamente aos seus interesses políticos e econômicos, tornou-se o ponto de partida para muitas pesquisas sobre programas televisivos. Na literatura produzida até os anos 1980, a televisão parecia ser colocada como se estivesse "fora da sociedade, reproduzindo ideologias e valores dominantes que seriam absorvidos ou repelidos, tal como emitidos, pelos telespectadores" (HAMBURGUER, 2005, p.18).

Porém, como destaca a antropóloga Nara Magalhães (2008), os estudos de recepção, que começaram a se desenvolver a partir da década de 1980, trazem consigo a possibilidade de releituras da mensagem realizadas pelos leitores-receptores. Assim, a abordagem das mediações se afirma como renovadora em termos paradigmáticos, em virtude de que a noção de mediação em Martín-Barbero (2003) emerge de uma visão (re)integradora dos fenômenos de comunicação, por meio do binômio comunicação-cultura (MAGALHÃES, 2008 e LOPES et al 2002). Desse modo, atualmente o processo de recepção é passível de um enfoque analítico distinto, por meio de uma perspectiva que pretende integrar todos os âmbitos da comunicação, tanto a produção, como o produto e a recepção.

Hamburguer (2005) alerta para o fato de que os estudos sobre recepção demonstram o caráter polissêmico que diferentes apropriações e interpretações de textos iguais, em contextos diferentes, implicam. A autora também destaca que o estudo sobre as telenovelas ainda se configura como um campo frutífero de pesquisa, uma vez que, dentre outros motivos, a forma como o texto televisivo interfere na determinação de leituras está intimamente relacionada com as mediações, visuais e auditivas dos telespectadores. E, como mostraremos a seguir, com os contextos culturais, as biografias e trajetórias de vida de seus espectadores.

\section{CAMINHO DAS ÍNDIAS E O PROCESSO DE RECEPÇÃO DA NARRATIVA SOBRE O SISTEMA DE CASTAS}

Dentre as peculiaridades da cultura indiana, o sistema de castas foi o sinal diacrítico mais recorrente na narrativa de Caminho das Índias, estando presente do início ao fim da trama, concomitantemente a outras questões. Nesta seção, apresentaremos um extrato de nosso trabalho de campo que, metodologicamente, se desenvolveu por meio da seleção de cenas da telenovela que foram gravadas por nós da internet e, posteriormente, levadas aos entrevistados para visualização, por meio de um notebook. Num primeiro momento, 
assistíamos às cenas juntos. E, logo após, desenvolvíamos conversas informais e entrevistas semiabertas sobre as mesmas.

Para a compreensão da cena apresentada a seguir, sobre a qual analisamos as considerações de nossos entrevistados, é preciso sublinhar que o sistema de castas na Índia é uma forma de organização social com base no princípio da hierarquia. $\mathrm{O}$ que determina que uma pessoa seja considerada de uma determinada casta é o seu nascimento, sendo o deus Brahma a figura de maior superioridade dentro desse sistema.

\subsection{Caminho das Índias apresenta: o sistema de castas entre os valores da hierarquia e da igualdade}

Relacionada à hereditariedade e permeada pela lógica religiosa, pode-se dizer (de modo superficial ${ }^{8}$ ) que as principais castas são quatro e que, junto delas, encontra-se uma classificação adicional em que se enquadram aqueles indivíduos considerados sem- casta.

A transcrição da cena conta com cinco personagens, Shankar, Puja e Hari, Opash e Ravi, onde eles representam uma situação de conflito demostrando que dentro do sistema de castas há divergência de opiniões. Ou seja, uns se posicionam em defesa do sistema em seu modo tradicional, com base no valor da hierarquia, enquanto outros se colocam a favor de algumas mudanças no sistema, com base no valor da igualdade.

$\mathrm{Na}$ mesma ordem da figura abaixo, da esquerda para a direita, o primeiro desses personagens é um sacerdote ${ }^{9}$, da casta Brahmani (que são os que nasceram da cabeça do deus Brahma). Na sequência, os outros dois personagens são Dalits ${ }^{10}$ (os sem-casta), também chamados de Intocáveis (que advêm da poeira que está sob os pés do deus Brahma). Os dois últimos são comerciantes ${ }^{11}$ (da casta Vaishas, que são os que nasceram das pernas do deus Brahma) ${ }^{12}$.

\footnotetext{
${ }^{8}$ Uma vez que o sistema de castas é extremamente complexo e possui uma infinidade de outras subdivisões e denominações que extrapolam esse número.

${ }^{9}$ Representado pelo ator Lima Duarte.

${ }^{10}$ Representados pelos atores Jandira Martini e Cadu Paschoal.

${ }^{11}$ Representados pelos atores Tony Ramos e Caio Blat.

${ }^{12}$ Ademais das duas castas descritas acima (Brahmani e Vaishas) fazem parte do grupo das quatro principais classificações, do referido sistema, os Xatrias (os guerreiros que nasceram dos braços de Brahma) e os Sudras (os servos, operários, camponeses que nasceram dos pés de Brahma). Vale ressaltar, que tanto a ortografia dos nomes das quatro grandes castas como as atividades exercidas pelos sujeitos de cada uma delas possuem variações em distintas fontes de pesquisa.
} 


\subsubsection{Transcrição da cena assistida pelos entrevistados}

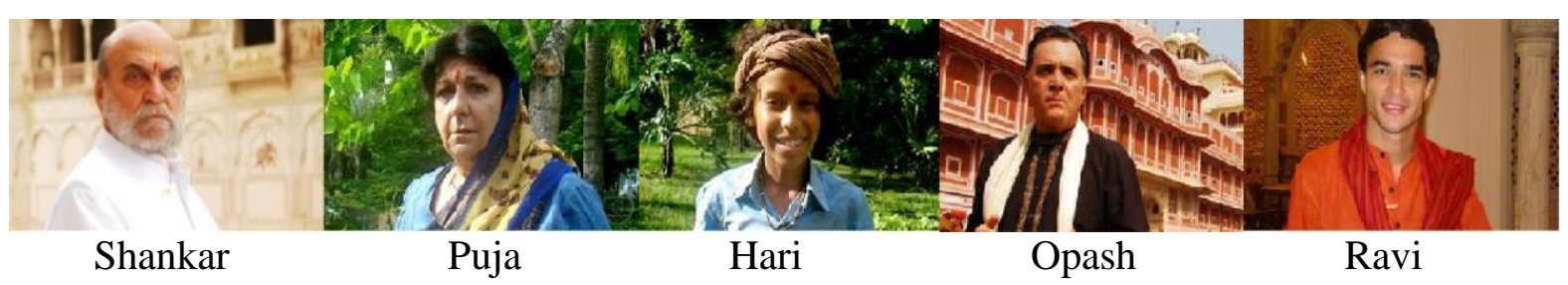

Fonte: http://caminhodasindias.globo.com/personagens acesso em ago/2009

Shankar: Antes de convencer os outros, vocês têm o dever de acreditar em vocês mesmos. E ver que vocês não são diferentes de ninguém, que também são filhos de Deus, nasceram de Deus como todos. Vocês têm o direito de frequentar escolas, de ser doutores...

Puja: Viu Hari? Tá ouvindo?

Shankar: Vamos fazer uma manifestação pelo direito dos Dalits de frequentarem escolas.

Opash (fala a Ravi): Veja, insuflando os Dalits! Onde está a polícia que não faz nada?

\subsection{O processo de recepção por parte dos entrevistados}

A cena que exibimos aos nossos entrevistados mostra, no espaço da rua, Shankar em pé, falando a um grupo de Dalits (entre eles Puja e o menino Hari) sobre seus direitos, e sendo aplaudido por eles. Shankar é da casta Brahmani, um homem rico e bem-sucedido, mas vira um renunciante de todo bem material, pois quer se tornar um homem santo. Esse personagem defende ideias pouco tradicionais com relação ao sistema de castas, como, por exemplo, a igualdade de direitos entre os Dalits (os sem-casta) e as pessoas de casta.

Enquanto Shankar fala aos Dalits, o grupo é observado de longe por Opash e seu filho Ravi, que mostram-se indignados com o que ouvem. Opash é comerciante, da casta Vaishas, e defende a hierarquia como princípio fundamental do sistema de castas. Assim, Shankar e Opash são rivais na trama, por defenderem dentro de um mesmo sistema, ideias antagônicas, principalmente sobre o lugar e os direitos dos Dalits naquela sociedade.

Após assistirem essa cena, o processo de recepção de nossos entrevistados centrou-se em três eixos de reflexão. O primeiro sobre um "erro" da telenovela com relação à narrativa sobre os Dalits. O segundo, sobre o processo de recepção dos brasileiros com relação a essa narrativa. E o terceiro, sobre certa ideia de homogeneidade cultural apresentada por Caminho 
das Índias, dando a entender (de forma equivocada) que toda a Índia podia ser representada pelos costumes e características de uma única região.

No que se refere ao primeiro eixo de reflexão, quanto aos Dalits, em termos gerais, para nossos entrevistados, a temática foi bem apresentada. Aliás, durante toda nossa pesquisa, pudemos observar que Caminho das Índias foi muito bem aceita por esses imigrantes indianos, vide os constantes elogios que manifestavam sobre a trama. Porém, o que foi pontuado por eles é que a segregação dos Dalits na Índia, conforme mostrado pela telenovela, condiz com uma realidade passada, que, em termos constitucionais, estava desatualizada, apesar de a narrativa da trama apresentar-se como contemporânea ${ }^{13}$. Nas palavras de nossos entrevistados:

Tem alguma tendência, uma corrente dentro da política, não tanto da religião, dentro da política do sistema democrático indiano, que há pessoas que são verdadeiramente favoráveis a uma certa reabilitação dos Dalits. E hoje em dia até tem partidos que são predominantemente de Dalits e dali tem a nível de estado, por exemplo, alguns estados que são governados pelos Dalits. (...) A constituição da Índia não aceita castas, castas é uma coisa que tá em vigor, que é muito forte, mas perante a lei eles são iguais a qualquer outro.

Olha, tudo verdade na novela. Mas agora mudou, mudou totalmente, anteriormente era assim (...), casta, cultura, Dalits... Foi super bem, Globo fez uma novela verdadeira, realmente que "tá", o que aconteceu, anterior, não agora. Agora modernizou.

É evidente que a característica mais enfatizada por Caminho das Índias sobre a sociedade indiana foi a segmentação oriunda de uma organização social hierárquica, por meio do sistema de castas e do grupo social dos Dalits. E, talvez, a trama optou por enfatizar essa característica justamente porque o traço moderno que mais se opõe ao sistema de castas é o da igualdade, e a negação moderna da hierarquia é o principal obstáculo que se impõe à compreensão desse sistema (DUMONT, 2008) ${ }^{14}$.

Se, por um lado, a narrativa de Caminho das Índias sobre os Dalits provocou a correção por parte de nossos entrevistados quanto à temporalidade desse processo,

\footnotetext{
${ }^{13}$ Ao ano de 2009, quando foi exibida.

${ }^{14}$ Para a reflexão sobre as narrativas da telenovela dialogamos, especialmente, com Dumont (2008). A título de esclarecimento, utilizamo-nos dessa referência apenas para contrapor alguns elementos da narrativa de Caminho das Índias sobre o sistema de castas indiano. De nenhuma forma, esse contraponto possui o intuito de identificar qual das fontes, se a narrativa da novela ou a obra de Dumont, possui a verdade, parcial ou absoluta, em relação ao sistema de castas. Trata-se, antes, de um recurso analítico, mesmo porque as temporalidades e historicidades são distintas.
} 
simultaneamente ao apreço pela representação fiel de um tempo passado, por outro lado, observamos que, entre telespectadores brasileiros, diferentemente desses imigrantes indianos, o processo de recepção dessa narrativa provocou estranhamento e rejeição. E esse foi o segundo eixo de reflexão que a cena suscitou aos nossos entrevistados, conforme ilustrado no depoimento a seguir:

Castas têm. Mas intocável (Dalits) pessoal brasileiro não gostou. Intocável, casta intocável, brasileiro não gostou. Mas, outro cultural o pessoal gostou, gostaram. Não gostou, mas ainda elas perguntam, aquela novela muito bonita, não tem nenhuma novela igual aquela, pessoal pergunta né? Porque aquela novela foi premiada oficialmente, internacionalmente.

De modo semelhante, o terceiro eixo de reflexão recaiu sobre o fato de que Caminho das Índias priorizou a exaltação de costumes de uma região específica da Índia, negligenciando as diversidades culturais presentes nas demais regiões daquele país e passando aos telespectadores uma visão em termos de homogeneidade. O que nossos entrevistados pontuaram foi que, assim como o Brasil, a Índia é um país composto por regiões de particularidades culturais bastante diversas. A negligência desse aspecto na narrativa da telenovela foi lembrada pelos entrevistados, conforme ilustra a colocação abaixo:

Bem, veja, a novela ela passa numa região da Índia que é o Rajistão, ela (a autora de Caminho das Índias, Glória Perez) escolheu aquela região eu não sei por quê. Mas, em todo caso, talvez, é uma região turística, é uma região de forte influência hindu, e é uma região bastante rica aquela região ali, o Jaipur, que é a capital da região, onde tem os grandes palácios. (...) Agora, têm algumas coisas aí, alguns detalhes que são típicos regionais, daquela região ali. Por exemplo, aquela indumentária muito rica, muito vermelha, já é da região do Rajistão e depois, e no resto ela (a telenovela) é bem feita.

A partir do processo de recepção dessa cena, de acordo com as observações realizadas por nossos entrevistados, apresentadas aqui por nós sob a forma classificatória de três eixos de reflexão, foi possível perceber que a história e as imagens transmitiam uma ideia de homogeneidade, tanto territorial/geográfica como de costumes/comportamentos sociais. Tratava-se, por vezes, de uma Índia genérica e estereotipada.

Entretanto, os entrevistados enfatizaram, em vários momentos, que as características da região em que se passava a telenovela estavam bem representadas, embora não todas as regiões possuíssem aquelas características. Ou seja, eles demarcaram as diferenças como ilustrado no seguinte depoimento: 
Música, dança, lá é como que cada estado é um país lá. Cada estado é um país, cultura diferente, língua diferente, vestido diferente, comida diferente, eles (referindo-se à telenovela) mostraram uma parte. Por exemplo, meu estado, Sul, aí é outra dança. Claro tá misturado aí, música misturada, dança misturada. Então a novela mostrou a música e a dança daquele estado.

E, em outro momento acrescentou também:

Olha, eles mostraram só rico (...) tudo família de rico.

Notamos como esses depoimentos vão ao encontro de reflexões produzidas em outras pesquisas acerca da relação entre os meios de comunicação e o processo de construção das identidades culturais. Um dos exemplos é o trabalho de Oliveira e Ronsini (2007), no qual as autoras afirmam que:

Os meios de comunicação ocupam papel importante na discussão sobre identidades, uma vez que eles disseminam, reforçam, constroem e desconstroem as representações hegemônicas em dado momento, apresentando novas identidades, remodelando outras, oferecendo mapas classificatórios pelos quais nos guiamos na interpretação e constituição de nossas próprias identidades e das identidades alheias (OLIVEIRA e RONSINI, 2007, p. 3).

Desse modo, podemos pensar que, mesmo levando em conta que a narrativa de uma telenovela possua um caráter ficcional, ela pode corroborar para a construção de estereótipos sobre modos de vida alheios. Ao demonstrar somente o aspecto mais aparente de um modo de vida, não adentrando na teia de significados ${ }^{15}$ em que elementos culturais e formas de organização social são construídos, pode-se incentivar determinados juízos equivocados sobre um tipo de organização social baseado em outros valores.

É bem provável que por esse motivo a situação dos Dalits, tal como apresentada por Caminho das Índias, tenha gerado nos brasileiros sentimentos de rejeição em relação aos personagens que segregavam e, de compaixão em relação aos personagens que eram segregados. Isso porque, como aponta Dumont (2008), o princípio igualitário e o princípio hierárquico são realidades primeiras e das mais cerceadoras da vida política de praticamente todas as formas de organização social vivenciadas pelo Homem. E, talvez, por parte do

${ }^{15}$ Baseamo-nos no sentido da expressão atribuída por Geertz (2008). 
público brasileiro, o processo de recepção da narrativa sobre os Dalits, acoplado aos sentimentos mencionados anteriormente, tenha sido mediado pela construção de uma analogia ao modo de vida e às relações díspares entre as diferentes classes sociais do Ocidente.

Mas, desde outra ótica, a de telespectadores indianos residentes no Brasil, é preciso enfatizar que, de acordo a nossos entrevistados, na cena em questão, a postura de Shankar (aquele que contesta a segregação dos Dalits) é a que representa a postura comportamental mais condizente com a realidade contemporânea da Índia.

Nesse sentido, é possível perceber que tanto na perspectiva de brasileiros como de imigrantes no processo de recepção:

(...) os telespectadores se valem do sistema de representações culturais configurado na identidade étnica para estabelecer relações com o conteúdo da telenovela. Nesta relação, ora o gênero é objeto de reconhecimentos, ora representa o outro, dependendo da relação que sua proposta estabelece com o conteúdo desta identidade (BONIN, 2002, p.5).

Além disso, percebemos que no processo de recepção de Caminho das Índias, os entrevistados sublinharam, também, a dinamicidade presente no âmbito da cultura. Os depoimentos alertam, de alguma forma, para o fato de que os indivíduos participam diferentemente de sua cultura e de que, por vezes, os padrões de um determinado sistema cultural não cobrem todas as situações possíveis, ou seja, há variações de comportamento e de opiniões (LARAIA, 2006).

Em suma, é possível inferir que, de modo específico, a cena aqui abordada sobre o enfrentamento entre tradição e modernidade, pretendia demonstrar que os agentes sociais têm a capacidade de questionar os seus próprios hábitos, modificá-los ou, mesmo, reforçá-los, evidenciando o caráter dinâmico das culturas e suas produções de sentidos (vide ORTNER, 2007; ABU-LUGHOD, 1997, 2003 e ZANINI, 2007). Também é possível inferir que, de modo geral, como alerta Bonin (2002), na recepção de uma telenovela um sistema de representação cultural é acionado, operando processos de reconhecimento e de diferenciação na relação com os personagens, as situações e os conflitos encenados.

E é nessa esteira de reflexão que damos sequência à próxima seção deste artigo, concentrando-nos nas particularidades do processo de recepção de telenovelas no Brasil. 


\section{AS PARTICULARIDADES DO HÁBITO DE ASSISTIR A TELENOVELAS NO BRASIL}

O olhar atento de nossos entrevistados, imigrantes indianos residentes no contexto urbano de Santa Maria (RS), em relação à narrativa da telenovela Caminho das Índias sobre a sua cultura e identidade étnica revela o quanto o hábito de assistir a telenovelas no Brasil pode ultrapassar o status de mero momento de entretenimento. Ao invés disso, podemos observar que:

As identidades, que são construtos individuais e coletivos que se refazem constantemente, têm na contemporaneidade dialogado intensamente com os meios de comunicação, em especial com a televisão e suas linguagens (ZANINI, 2005 p. 5).

Entre os inúmeros programas televisivos a telenovela, especialmente a telenovela das oito, é um produto midiático muito presente no cotidiano, tanto dos brasileiros como de imigrantes que vêm residir no Brasil. Nesse último caso, ela potencializa a noção de pertencimento a uma comunidade imaginada (ANDERSON, 1983) e, desterritorializada porque circulante (APPADURAI, 1997).

A telenovela, por meio de seus personagens e situações cotidianas, também promove uma socialização mediante aquele mundo brasileiro apresentado. E a complexidade desse processo é investigada por muitos autores que sinalizam as diversas formas pelas quais a telenovela faz parte do cotidiano, da rotina e do modo de vida das pessoas residentes no Brasil.

Segundo Leal (1990), programas desse gênero têm como característica uma cíclica promoção de ídolos $^{16}$, tornando os atores familiares e íntimos, através da sua constante exposição via imagem e som. Junto a isso, a autora observa que, nas casas onde realizou sua pesquisa, é ao entardecer que se liga o televisor e, a partir desse momento, o aparelho passa a funcionar também como um relógio da casa. Esse costume, constatado pela autora é, de fato, uma realidade recorrente em grande parte dos lares brasileiros, mesmo hoje em dia com o uso massivo da internet e de suas ferramentas mais populares, como as chamadas redes sociais. $\mathrm{Na}$ falta de um relógio por perto, se a televisão estiver ligada, pode-se ter mais ou menos uma

\footnotetext{
16 Observa-se, também, nos dias atuais, que outros meios de comunicação de massa corroboram com esse processo, veiculando informações e imagens sobre as vidas pessoais dos atores, como, por exemplo, os "programas de fofocas" presentes no rádio e na internet.
} 
noção da hora, em função de estar passando a telenovela das 6, das 7 ou das 8. Em outras palavras, as telenovelas também funcionam como um marcador de tempo do cotidiano doméstico.

Outro apontamento de Leal (1990), que nos é familiar, diz respeito ao fato de que os jargões das telenovelas (modismos da fala cotidiana) podem ser facilmente detectados e interpretados pelas crianças. Contudo, também observamos que tais jargões são frequentemente reproduzidos também pelos adultos, como um costume dos telespectadores que retrata uma atitude simpática em relação aos personagens das telenovelas. E essa relação dos telespectadores com as telenovelas e seus personagens pode ir muito além, conforme é descrito nas seguintes colocações ${ }^{17}$ :

Há forte relação emocional com os espectadores, que discutem atitudes e destino de personagens como se fossem pessoas reais, xingam na rua os atores como se fossem responsáveis pelas vilanias que cometem na ficção, escrevem cartas aos milhares expressando a sua aprovação ou reprovação pela maneira como o autor está conduzindo a trama. Esta relação é que faz da telenovela um gênero único, capaz de parar o País, fechar cinemas, restaurantes, teatros, alterar horários de jogos de futebol e seções da Câmara e do Senado, mantendo, no horário sagrado, mais de cinqüienta milhões de brasileiros diante da telinha (ALENCAR, 2002).

Outra análise importante e presente nos estudos sobre as telenovelas brasileiras, notadamente as da Rede Globo de Televisão (ALMEIDA, 2003 e ALENCAR, 2002), referese à questão do consumo. Almeida (2003) analisa a relação entre telenovela e formação de hábitos de consumo em suas interfaces com a construção de gênero. A autora realiza uma etnografia de recepção da telenovela $O$ Rei do Gado com famílias de camadas médias e populares. A questão da interação entre publicidade e televisão é central na sua pesquisa, pois considera que a televisão é a maior mídia no Brasil, e que ela funciona de maneira muito eficaz para vender uma ampla gama de produtos. Ao se espalhar pelo país em quase toda a sua extensão e ao penetrar amplamente nos lares brasileiros, a televisão torna-se uma das mídias mais usadas pela publicidade. Em outros termos:

A novela permite que o espectador se familiarize com uma variedade de mundos sociais diferentes de seu universo particular, com diversos estilos de vida e os bens e serviços associados a estes mundos e estilos. A novela

\footnotetext{
${ }^{17}$ As referidas colocações foram realizadas pelo ator Paulo José e correspondem à parte do extrato da contracapa do livro de Alencar (2002).
} 
permite a exposição constante de vários estilos de vida e produtos que podem ser consumidos para a construção destes estilos (ALMEIDA, 2003, p.31).

De modo semelhante, Alencar (2002) analisa a questão do consumo como fruto da interação entre os telespectadores e as telenovelas, em que, por meio de um mecanismo de identificação, os noveleiros ${ }^{18}$ se tornam consumidores de elementos que caracterizam o estilo de vida enfatizado positivamente pela trama. Para Alencar (2002), a posse de tal objeto, a adesão à determinada aparência, a imitação de tal postura ou a repetição de tal bordão podem alimentar em alguém a ideia de pertencer a um grupo social dito dominante ou que está em voga. O autor ilustra tais colocações utilizando-se de exemplos da telenovela Terra Nostra, exibida pela Rede Globo entre os anos de 1999 e 2000, que tinha como eixo temático o processo de imigração italiana. Conforme Alencar (2002):

Terra Nostra quase coloca todas as dietas abaixo, pegando o telespectador pelo estômago com o "macarron" da personagem Paola de Maria Fernanda Cândido. E não ficou só nisso. Macarrão, vinho, molho de tomate e até pratos com a marca da atração da Globo invadiram os supermercados. A Adria lançou a linha de massas Terra Nostra. A Arisco, o extrato de tomate e o molho refogado Terra Nostra. Para acompanhar a macarronada, vinhos tinto e branco da Cooperativa Vinícola Aurora. Foi a onda da culinária italiana conquistando as mesas dos telespectadores do País inteiro, as revistas e as colunas de culinária, os programas de culinária na televisão (ALENCAR, 2002, p. 100).

Assim, nota-se como a telenovela é produto, produtora e mediadora cultural de gostos, estilos e valores. Seja através da disseminação de novas expressões idiomáticas, seja como veículo de incentivo de determinados objetos de consumo, seja pela identificação ou rejeição de seus personagens por parte do público, o hábito de assistir telenovelas faz parte do modo de vida de brasileiros e de estrangeiros que residem no Brasil. Se pensarmos "a televisão como um meio reflexivo e a recepção como um processo dialógico e criativo pelo qual os grupos e indivíduos podem pensar sobre si mesmos e sobre suas trajetórias" (Zanini, 2005, p.7), veremos a telenovela como um instrumento que, potencializa, especialmente para grupos migrantes, construções mnemônicas e releituras do mundo de origem (Zanini, 2007c) e também da terra hospedeira.

Considerando-se que as memórias são leituras sobre o passado elaboradas no presente (Halbwachs, 1990), observa-se o quanto as telenovelas, suas tramas, personagens e enredos

${ }^{18}$ Como são chamados, popularmente, os telespectadores assíduos das telenovelas. 
possibilitam processos dialógicos de produção de sentidos, significados e pertencimentos identitários.

\section{CONSIDERAÇÕES FINAIS}

Por meio desta pesquisa, acompanhamos o processo de recepção de imigrantes indianos residentes no contexto urbano da cidade de Santa Maria (RS) da telenovela Caminho das Índias. Uma telenovela que suscitou concordâncias, discordâncias, correlações e analogias entre os costumes e modos de vida de brasileiros e indianos.

Em meio a conjunto de mediações e reapropriações de sentido pudemos perceber que nossos entrevistados estavam muito envolvidos por essa telenovela, porque a nosso ver, através de Caminho das Índias eles puderam reviver, relembrar e ressignificar algumas das particularidades de sua cultura, já um pouco esquecidas ou atenuadas em função dos quase 30 anos de migração e de vida no Brasil.

Notamos o quanto a narrativa de uma telenovela sobre a identidade étnica de um grupo pode adquirir um papel significativo, dialógico e promotor de reflexividades, pois ela tem a faculdade de apresentar a um grande público novas identidades, bem como de construir e desconstruir representações hegemônicas. Do mesmo modo, julgamos importante atentar para o fato de que o mesmo potencial que a narrativa midiática possui de propiciar ao telespectador a reflexão e o encontro com outras realidades também o tem para difundir valores e reforçar consensos, nem sempre condizentes ao modo como os grupos sociais se autorreferenciam e/ou à forma como desejam ser identificados.

Por um lado, o exercício proposto nesta pesquisa nos permitiu refletir de forma específica sobre o processo de recepção de imigrantes acerca da narrativa sobre suas identidades étnicas veiculada por uma telenovela. Por outro lado, esse mesmo exercício nos possibilitou desenvolver uma reflexão mais geral sobre as telenovelas como um hábito brasileiro.

Ilustramos as particularidades desse hábito trazendo ao texto exemplos de outros estudos que demonstram que as telenovelas não funcionam somente como um meio de diversão, mas como um marcador de tempo, um veículo de promoção de ídolos, e incentivo de hábitos de consumo. Também, elas funcionam como um veículo de aproximação com outras realidades culturais, de disseminação de jargões e neologismos, que adquire uma forte 
relação emocional com seus telespectadores, seja via as afinidades ou aversões provocadas por suas personagens e histórias.

Em suma, esse veículo comunicacional, a telenovela, que provoca tantas ações e reações em seus telespectadores e que se constitui como um hábito cotidiano do modo de vida de brasileiros e estrangeiros que residem no Brasil, configura-se como um rico objeto de pesquisa para a área da Antropologia quando dialoga com os conhecimentos produzidos pela área da Comunicação como os estudos dos processos de recepção, e dos elementos que atuam como mediadores desses processos.

\section{REFERÊNCIAS}

ABU-LUGHOD, Lila. The interpretation of culture(s) after television. 1997. Disponível em <www.haussite. net/haus.o/script/txt2001/01/lughod.html>. Acesso em 17 Ago. 2005.

ABU-LUGHOD, Lila. Melodrama egípcio: uma tecnologia do sujeito moderno?

Cadernos_Pagu, Campinas, n.21, 2003.Disponível_em

$<$ http://www.scielo.br/scielo.php?script=sci_arttext\&pid=S01043332003000200005\&lng=en\&nrm=is o>. Acesso em 29 Out. 2013.

ALENCAR, Mauro. A Hollywood brasileira: panorama da telenovela no Brasil. Rio de Janeiro: Senac, 2002.

ALMEIDA, Heloisa Buarque de. Telenovela, consumo e gênero: "muitas coisas mais". Bauru, SP: EDUSC, 2003.

ANDERSON, Benedict. Imagined Communities. London: Verso.1983.

APPADURAI, Arjun. Soberania sem territorialidade. Notas para uma geografia pós-nacional. Novos Estudos Cebrap, 49, 1997, pp.33-46.

BARTH, Frederik. Grupos étnicos e suas fronteiras. In: Teorias da etnicidade. POUTIGNAT, Philippe, STRIFF-FENART, Jocelyne. São Paulo: Unesp, 1998.

BLANC, Linda, GLICK_SCHILLER, Nina e SZANTON, Cristina. Transnationalism, Nation-States, and Culture. Current Anthropology, vol. 36, n. 4 (Aug. - Oct., 1995), pp. 683-686. Disponível em http://www.jstor.org/stable/2744260. Acesso em: 08 de Set. 2011.

BONIN, Jiani A. Identidade étnica e telenovela. Ciberlegenda, n. 10. 2002. Disponível em: <www. uff.br/mestcii/jianni1.htm>. Acesso em 01 Set. 2009.

BORELLI, SILVIA HELENA SIMÕES. Telenovelas brasileiras: balanços e perspectivas. São Paulo Perspec., São Paulo, v. 15, n. 3, July 2001 . Disponível em

$<$ http://www.scielo.br/scielo.php?script=sci_arttext\&pid=S01028392001000300005\&lng=en\&nrm=is o>. Acesso em 30 Out. 2013. 
DUMONT, Louis. Homo Hierarchicus: O Sistema de castas e suas implicações. 2 ed. São Paulo: Editora da Universidade de São Paulo, 2008.

GEERTZ, Clifford. A Interpretação das Culturas. Rio de Janeiro: LTC, 2008.

HAMBURGER, Esther. O Brasil antenado: a sociedade da novela. Rio de Janeiro: Jorge Zahar Ed, 2005.

HALBWACHS, Maurice. A memória coletiva. São Paulo: Vértice, Editora Revista dos Tribunais, 1990.

KOTTAK, Conrad P. Primi-time society. An Anthropological analysis of television and culture. Belmont, Wodsworth Publishing Company, 1990.

LARAIA, Roque de Barros. Cultura: um conceito antropológico. 19 ed. Rio de Janeiro: Jorge Zahar Ed., 2006.

LEAL, Ondina Fachel. A leitura social da novela das oito. 2.ed. Petrópolis: Vozes, 1990.

LOPES, Maria Immacolata Vassallo de; BORELLI, Silvia Helena Simões; RESENDE, Vera da Rocha. Vivendo com a telenovela: mediações, recepção, teleficcionalidade. São Paulo: Summus, 2002.

MAGALHÃES, Nara Maria Emanuelli. Eu vi um Brasil na TV: televisão e cultura em perspectivas antropológicas. Santa Maria: Ed. da UFSM, 2008.

MARTÍN-BARBERO, Jusús. Dos meios às mediações: comunicação, cultura e hegemonia. Rio de Janeiro: UFRJ, 2003.

OLIVEIRA, Vanessa de; RONSINI, Veneza Mayora. Ativismo negro: afirmação étnica e reprodução do racismo na mídia. In: Anais do VIII Congresso Brasileiro de Ciências da Comunicação da Região Sul. Passo Fundo: Editora da UFP, 2007.

ORTNER, Sherry B. Subjetividade e crítica cultural. Horizontes Antropológicos. Porto Alegre, ano 13, n. 28, p. 375-405, jul./dez. 2007. Disponível em:

http://www.scielo.br/pdf/ha/v13n28/a15v1328.pdf. Acesso em: 20 Jan. 2010.

PECIAR, Paola L. R. A Cultura e a identidade étnica dos indianos presentes na narrativa televisiva da novela Caminho das Índias. [monografia de graduação]. Santa Maria: Curso de Graduação em Ciências Sociais da UFSM, 2010.

PROJETO MEMÓRIA GLOBO. Guia Ilustrado TV Globo: novelas e minisséries. Rio de Janeiro: Jorge Zahar, 2010.

ZANINI, Maria Catarina Chitolina. Assistir, ouvir, ler e narrar: o papel da mídia nas construções identitárias étnicas. In: Revista de Antropologia. Vol.48 n² São Paulo, 2005.

ZANINI, Maria Catarina Chitolina. Fé, trabalho e família: a construção das memórias entre descendentes de imigrantes italianos. Revista USP, v. 72, p. 161-170, 2007.

Imagem: Personagens de Caminho das Índias. Disponível em <http://caminhodasindias.globo.com/platb/files/1112/2009/09/fotao3novo.jpg> Acesso em: 02 Mar. 2010 . 
Doutorado em Antropologia Social pela Universidade Federal de Santa Catarina, UFSC. Mestrado em Educação, Pós-Graduação em Educação Ambiental, Licenciatura em Sociologia e Bacharelado em Ciências Sociais pela Universidade Federal de Santa Maria, UFSM. Bacharelado em Turismo pela Universidade Franciscana, UFN. Possui experiência de investigação nas áreas da Antropologia, da Educação e do Turismo. Atualmente dedica-se a pesquisas sobre o modo de vida das cidades contemporâneas e sobre o exame do método etnográfico, especialmente, no âmbito da Antropologia Urbana. Pesquisadora/colaboradora do Núcleo de Dinâmicas Urbanas e Patrimônio Cultural

(NAUI/PPGAS/UFSC).

\section{Maria Catarina Chitolina Zanini}

Possui graduação em Curso de Ciências Sociais pela Universidade Federal do Rio Grande do

Sul- UFRGS (1987), mestrado em Antropologia pela Universidade de Brasília- UnB (1997), doutorado em Ciência Social (Antropologia Social) pela Universidade de São Paulo- USP (2002) e

Pós-doutorado pelo Museu Nacional (MN-UFRJ) (2008). Atualmente é Professora Titular da

Universidade Federal de Santa Maria (UFSM), vinculada aos Programas de Pós-Graduação em

Ciências Sociais e Programa de Pós-Graduação em História. Coordenadora do NECON/UFSM

(Núcleo de Estudos Contemporâneos). Membro do Comitê de Iniciação Científica e de Inovação Tecnológica da UFSM. Tem experiência na área de Antropologia, trabalhando principalmente com as seguintes temáticas: migrações, teoria antropológica, campesinato e etnicidade. Visiting Schoolar na Universitá Ca Foscari Venezia (Itália). Pesquisadora Associada do NIEM-UFRJ (Núcleo de Estudos Migratórios). Pesquisador Associado ao Instituto Histórico de São Leopoldo. Membro do MigraidhUFSM e da Cátedra Sérgio Vieira de Mello UFSM. Pesquisador PQ 2/CNPq.

\section{@ $\odot \Theta \odot$}

Esta obra está licenciada com uma Licença

Creative Commons Atribuição-NãoComercial-CompartilhaIgual 4.0 Internacional 